\title{
Special feature: Professor Masahiko Aoki's conception of economics and institution
}

\author{
Kiichiro Yagi ${ }^{1}$
}

Published online: 13 November 2017

(C) Japan Association for Evolutionary Economics 2017

Prof. Masahiko Aoki (1938-2015) was a special figure to many of the members of the Japan Association for Evolutionary Economics. Since his return to Japan in 1972 from United States as one of the most ambitious theoretical economists, he provided young economists in Japan with ever fresh ideas that stimulated their research. It was one of the sources of the evolutionary and institutional directions in Japan that flowed into the foundation of this association in 1997. Thus, we are happy that we can here provide a special issue dedicated to him in addition to the two obituaries that appeared in number 2 of volume 12 already.

The contribution of Carsten Herrmann-Pillath (2016) as well as that of Hirokazu Takizawa (2017) in this special feature are results of the special session "Professor Aoki's conception of institution" of the 20th annual meeting of that association held at the University of Tokyo on March 26-27 2016. In this special feature, we could add the contribution of Yoshinori Shiozawa (2017) who had been a close younger colleague of Prof. Aoki at the Institute of Economic Research, Kyoto University in 1970s and 1980s. Shiozawa reveals Aoki's relatively unknown attempt to formalize the dynamic adjustment process of market economy. Further, we hope that we can publish several contributions more in the future issues that are motivated by Prof. Aoki's ideas.

\section{References}

Herrmann-Pillath C (2016) Institutional naturalism: reflections on Masahiko Aoki's contribution to institutional economics. Evol Inst Econ Rev. https://doi.org/10.1007/s40844-016-0037-2

Kiichiro Yagi

yagi@econ.setsunan.ac.jp

1 Setsunan University, Neyagawa-shi, Osaka, Japan 
Shiozawa Y (2017) Professor Aoki when he was interested in dynamic processes in the market economy. Evol Inst Econ Rev. https://doi.org/10.1007/s40844-017-0083-4

Takizawa H (2017) Masahiko Aoki's conception of institutions. Evol Inst Econ Rev. https://doi.org/10. 1007/s40844-017-0087-0 